BRITISH JOURNAL OF

\section{INDUSTRIAL MEDICINE}

\author{
LONDON, April, 1945
}

\section{HEALTH IN THE SHIPPING INDUSTRY}

Sea transport is a vital British industry and the health of those who work in it is of high importance. The number of men employed in the shipping industry is comparatively small considering the immense work it accomplishes and the fact that it comprises some 30 per cent. of the world's gross tonnage. $^{1}$ In June, 1942, the number of British merchant seamen was estimated at 120,000 -equal to about eight army divisions. This group included 4530 masters, 12,950 deck officers, 19,800 engineers, 35,400 deck ratings, 29,000 engineer ratings and 17,400 stewards. Even if we add to this some 45,000 Indians (or lascars), over 6000 Chinese and a number of Arabs, the total personnel is less than 200,000. ${ }^{2}$ Nevertheless the hazards in this industry are great: the risk of collision, of grounding on rocky coasts in heavy seas, fire and explosion. There are also hazards to health which are less dramatic perhaps but equally significant. The mortality rates of merchant seamen between the ages of 20 and 64 are approximately double the standard rate for the same age group, the death rate from tuberculosis among seamen being four times greater than among the general population. ${ }^{3}$ It has also been shown that $\mathbf{1 7}$ per cent. of all deaths occurring within a year of leaving the sea are due to tuberculosis. ${ }^{4}$ More recently it has been noticed that merchant seamen arrive for treatment in a more advanced stage of the disease than do the general public, ${ }^{5}$ and over-crowding in quarters at sea is considered the chief cause of this. Venereal disease is responsible for approximately 10 per cent. of illness among mérchant seamen. ${ }^{6}$ The welfare of the seaman in port is a matter for concern, and it is of interest to see that a Government report on this has just been published. ${ }^{7}$ It is estimated that throughout his working life a seaman spends on an average two months in twelve ashore, and during this time he has ample opportunity for contracting disease: the incidence of venereal disease is higher in the ports than anywhere else. In addition to welfare, measures must be taken to conserve health. If some form of 'pool' system is to remain-and it has much to commend it on sociological grounds -then it could well be a medium for the develop-

1 Whitaker's Almanack, London, 1945; p. 199.

3 Registrar-General's Decennial Supplt. 1931.; Pt. II. Occupa3 Registrar-General's Decennial Supplt.
tional Mortality (1938). H.M.S.O.

4 Home, W. E. (1934). Lancet, 1, 1081.

6 Lancet, 1945, 1, 279.

7 Lancet, 1945, 1, 279. appointed by the Minister of Labour and the Minister of War Transappointed by the Minister of Lab
port in 1943. H.M.S.O., Lond. ment of medical supervision of seamen ashore. Because the need had become so obvious the docks medical service at one large port already caters for seamen, as apart from dockers, by private arrangement and entirely in a voluntary capacity. Here is an interesting link-up between two branches of industrial medicine.

The contribution by Dr. Jameson Carr to this subject in this number of the Journal is opportune. Some of the conclusions arrived at need immediate attention: for example, the urgent health requirements of the smaller vessels, particularly freighters, where there is no doctor and sick quarters are inadequate; the need for improving crews' quarters generally; and the institution of preemployment and follow-up medical examinations throughout the industry. Pressure must be brought to bear on the appropriate companies to improve matters. The difficulty of deciding what authority to approach is an example of the need for integration of our national health services. The Ministry of War Transport is, as its name suggests, a temporary body; medical services at the Ministry of Labour are mainly concerned with factories; and the Board of Trade is said to be conservative of existing interests and unlikely to suggest or impose reforms on unwilling companies. As the port medical officer has much to do with ships, their passengers, and their crews, it might be reasonable for his parent body, the Ministry of Health, to play a larger part in preserving the health of merchant seamen than it has in the past. If individual companies, represented perhaps by the Shipping Federation Limited, and trade unions such as the National Union of Seamen and the Navigators' and Engineer Officers' Union, got together to discuss this matter with representatives of the medical profession some good would surely result. It is interesting to note that the Royal College of Physicians of London propose to issue a report on this subject in the near future. ${ }^{8}$ It is hoped that they will marshal the available evidence in favour of better health supervision of this branch of industry in such a manner that the country will be convinced of the need for reform. It may be that one way of doing this would be to appoint doctors to survey the position on the spot. Health surveys in different industries could well constitute the next advance in research method, for matters such as these present a live challenge to modern medicine.

The trade unions have already outlined their views in the International Seafarers' Charter. ${ }^{9}$ This has been adopted in principle by the International Commission - the joint International Labour Office committee of seamen's and shipowners' organizations - and the Governing Body of the I.L.O., and will serve as a basis for discussion at an International Maritime Conference to be held in October, 1945, to which twenty countries are to be invited. It is hoped that doctors with experience of maritime medicine will be among the " necessary

8 Second Interim Report of Social and Preventive Medicine

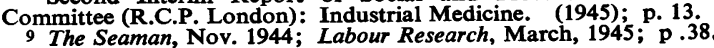


technical advisers' who will also attend the Conference. The Charter includes important recommendations on living conditions, hygiene and medical services. It points out that conditions in British ships compare unfavourably with those of the U.S.A. and a number of continental countries; and that in 1938 the death rate for tuberculosis among seamen was 47 per cent. above the national average and the death rate for duodenal ulcer 32 per cent. above. Wood for bunks, furniture and floors should be replaced by metal or plastic materials to safeguard against vermin. Beds and bedding, including sheets, should be supplied by the shipowners. Adequate heating and ventilation should be provided by an air-conditioning system. There is an urgent need for good lavatory accommodation, a ship's laundry, and a drying room for the men's use. All ranks should pass a medical examination before going to sea. Finally, the Charter recommends that there should be better food and feeding arrangements; cooks should be properly trained; and galleys in all new ships should be provided with refrigerators and other modern kitchen equipment.

The doctor in close daily contact with the merchant seamen-the worker in this industry-is the ship surgeon. $\mathrm{He}$ is an industrial medical officer no less than his colleague in the factory. The number of permanent ship surgeons in peacetime is estimated at about 300 . In addition perhaps 1000 ships employ temporary surgeons who sail for one or two voyages. British ship surgeons, unlike those in certain other countries, are not required to attend courses in maritime hygiene. Whether such courses should be compulsory or not is beside the point: here is an immediate field for post-graduate training. Courses in this branch of industrial medicine must include the general principles of ship construction, hygiene of crews' quarters, ventilation, heating and lighting; dietetics and food storage; knowledge of diseases such as cholera, plague, yellow fever, typhus and smallpox, and the problems of disinfection and disinfestation; modern treatment of medical and surgical emergencies; and the various legal requirements which concern the shipping industry. Above all the ship surgeon must be trained in the principles of preventive medicine, and he must be selected as much for his personal character and outlook in this direction as for his technical skill. Properly organized courses of instruction should be started at the Universities of London, Liverpool and Glasgow, at the earliest opportunity; these should be the responsibility of a University Department of Industrial Medicine. Thus as a profession we could make a contribution now to a national problem of much urgency.

\section{TRINITROTOLUENE}

TNT is the symmetrical trinitro derivative of toluene; it was first made in the laboratory by the German chemist Hepp in 1860 , and was first put to use as an explosive by the German military authorities in 1902. Present-day explosives fall broadly into three divisions: initiators, of which the principal ones are mercury fulminate and lead azide; intermediates, for which tetryl is almost exclusively used; and the main explosive charge for which, until recently, a TNT mixture was always used. In peace-time TNT is used in blasting operations.

At first TNT was thought to be a non-toxic substance and Prosser White ${ }^{1}$ showed that dinitrobenzene was more toxic to animals than TNT. Koelsch ${ }^{2}$ stated that pure, recrystallized TNT does not possess the toxic properties observed with the crude material. In his view serious toxic effects from fairly pure material are exceptional, and the degree of contamination is the decisive factor in its toxicological action. Yet in the last war the first fatal case in England occurred as early as February 1915. It soon became evident that the substance caused five definite clinical syndromes: dermatitis, methaemoglobinaemia, gastritis, toxic jaundice, and aplastic anaemia. The clinical picture has recently been well described by von Oettingen. ${ }^{3}$ These diseases affected so many workers that on January 1, 1916 , toxic jaundice was made a notifiable disease, and as a result 181 cases with 52 deaths were notified in 1916,189 cases with 44 deaths in 1917 , while the greater knowledge of the danger and the introduction of preventive measures reduced the notifications in 1918 to 34 cases with 10 deaths. In the same period there were 15 cases of aplastic anaemia, all of which were fatal. The situation in 1916 was serious, and the Medical Research Council initiated much research as a result of which Moore ${ }^{4}$ was able to show that the usual route of absorption of TNT was through the skin, but von Oettingen and his co-workers ${ }^{5}$ have disproved this conception and shown that absorption through the skin is insignificant compared to inhalation or ingestion from the alimentary tract. Webster ${ }^{6}$ devised a valuable chemical test for demonstrating the presence of TNT derivatives in the urine, and this test was improved by Ingham, ${ }^{7}$ making it sensitive to 1 part in 10,000 . Von Oettingen developed spectrophotometric methods for the determination of 2,6 dinitro-4-aminotoluene and other derivatives of TNT in biological materials. Panton ${ }^{8}$ showed that toxic jaundice and anaemia appeared to be separate pathological states. Anaemia might occur without jaundice and only 17 per cent. of the jaundiced patients became anaemic, while Turnbull ${ }^{\circ}$ found at necropsy a fatty marrow throughout the long bones. in two fatal cases of aplastic anaemia, the liver being rusty brown from an excess of iron pigment. Minot ${ }^{10}$ suggested that TNT caused both increased destruction and increased formation of red blood

1 Lancet, 1901, 2, 582, 709.

Zbl. Gewerbehyg., 1918, 6, 15, 26, 53, 66, 88

U.S. Publ. Hlth. Bull. No. 271, 1941

Spec. Rept. Ser. Med. Res. Com. Lond., 1917, No. 11

U.S. Publ. Hlth. Bull. No. 285, 1944.

6 Lancet, 1916, 2, 1029 ; Spec. Rept. Ser. Med. Res. Com. Lond., 1921 , No. 58.

Lancet, 1941, 2, 554

8 Ibid., 1916, 2, 77.

9 Proc. roy. Soc. Med., 1917, 10, 47

10 J. industr. Hyg., 1919, 1, 301 